\title{
Os Estados nacionais frente à globalização
}

\author{
MARIO RAPOPORT
}

Há quinze anos o mundo parecia haver alcançado um ponto de estabilização para Estados, nações e fronteiras por causa do duplo efeito da Guerra Fria e uma descolonização que estava terminando. Mas a queda do Muro de Berlim, com o desmoronamento do Império Soviético, e os processos de globalização e regionalização em curso mudaram radicalmente a situação.

Uma das principais questões que economistas e cientistas políticos e sociais discutem atualmente é a do "debilitamento" ou possível "desaparecimento" do Estado-Nação, baseados na idéia de que até o fim da bipolaridade teria dominado, no cenário internacional, o "paradigma” do Estado-Nação soberano e autárquico. Com o triunfo do capitalismo liberal e a globalização econômica, estaríamos presenciando um processo de diminuição progressiva da esfera de ação dos Estados, fato em relação ao qual concordam tanto apologistas quanto críticos do neoliberalismo.

Por exemplo, Richard Falk e Gilles Breton desenvolveram o conceito de "evasões do Estado" para mostrar como dentro e fora das fronteiras de um Estado-Nação existem forças internas e externas que estabelecem redes ou efetuam ações que, sem inserir-se necessariamente em uma lógica de oposição aos Estados, prescindem de seus marcos ou normas institucionais. Mencionam, assim, as redes que atuam "por sobre os Estados" (grupos, empresas ou movimentos internos que procuram modificar políticas em um sentido transnacional), “através das fronteiras” (grupos externos que se apoiam sobre princípios transnacionais para pressionar os Estados) ou "ainda mais além das fronteiras” (grupos que se dedicam a resolver políticas globais ou têm aspirações globais: direitos humanos, movimentos ecológicos, fundamentalismos diversos, tráfico de drogas, etc. $)^{1}$.

Isso é certo em grande medida. Ninguém pode negar a existência desses fenômenos de transnacionalização (desde empresas multinacionais e organizações não-governamentais de cooperação até máfias ou organizações terroristas) que colocam em questão o papel dos Estados-Nações ou debilitam suas soberanias. É preciso, entretanto, incorporar à análise certos elementos que relativizam essas visões. Antes de tudo, deve-se evitar uma assimilação mecânica entre o conceito de Nação e o de Estado, o que freqüentemente resulta de uma perspectiva 
eurocêntrica baseada no processo histórico de formação de alguns países da Europa Ocidental, cujo paradigma seria a França. Como definir, por exemplo, no âmbito da própria Europa, países como Suíça e Bélgica, onde coincidem um Estado e uma sociedade plurinacional? Isso é mais evidente ainda em outras partes do mundo, como na Índia ou no Canadá. Em sentido oposto, existem nações que não puderam transformar-se em Estados.

A Nação, do latim natus, é uma categoria histórica vinculada a processos materiais e culturais que permitem constituir uma comunidade distinta em relação a outras (ou, dito de outro modo, com uma identidade própria). Está ligada, ademais, às formas de evolução social que caracterizaram o desenvolvimento do capitalismo desde seu início. Ao mesmo tempo, as nações, com maior ou menor êxito, procuraram estabelecer-se como Estados, quer dizer, possuir um aparato de poder (órgão de ação e coerção) com soberania sobre o território dessa nação e com o objetivo de regular as relações dentro da sociedade nacional e com as outras comunidades. No mundo moderno, esses processos resultaram num sistema mundial formado por povos que possuem Estados juridicamente reconhecidos ${ }^{2}$.

Com base nestas premissas, podemos nos perguntar se existe hoje um debilitamento generalizado do Estado-Nação como conseqüência do processo de globalização e qual o sentido do mesmo.

Em princípio, confunde-se muitas vezes o "debilitamento" do Estado com um fenômeno distinto, ainda que fortemente associado ao processo internacional e ao pensamento que o acompanha: o processo de mudança das políticas econômicas predominantes, marcadas pela crise do modo de regulação keynesiano e pela aplicação, em seu lugar, de políticas neoliberais de ajuste estrutural (re-estruturaçao produtiva, reforma do Estado, abertura econômica, privatizações, abandono de políticas de proteção social). Isso pode implicar um Estado menor, com menos burocracia, mas não por isso menos "forte", quer seja no interior da sociedade nacional como em suas relações externas. No caso dos países desenvolvidos, é particularmente notável seu papel como instrumento para garantir maior competitividade de cada um deles. Nos países periféricos, por seu turno, ainda é preciso analisar se as políticas de ajuste estrutural, os efeitos do endividamento externo e a redução das áreas de capitalismo do Estado podem ou não incrementar os níveis de competitividade. Em todo caso, como assinala um autor, no plano econômico a regulação estatal subsiste, ainda que seja no sentido de retomar os objetivos que tinha "em um período mais recuado do capitalismo ocidental, visando à competitividade, à supremacia e ao elitismo” no lugar dos traços predominantes no chamado "Estado do bem-estar" surgido no pós-guerra, vinculando-se a políticas de crescimento, equilíbrio social e universalidade. Hoje "a soberania do Estado, que não é juridicamente posta em questão pela afirmação das tendências em curso, reduz-se de fato, para os 
governos, a determinar soberanamente até onde irá sua adequação aos (movimentos externos de) capitais."

Outro aspecto, que distorce o enfoque deste problema, é que se parte de um pressuposto falso ao conceber o cenário das relações internacionais anterior como regido pela ação exclusiva dos Estados. Precisamente ao longo dos últimos cem anos fizeram-se fortemente visíveis os fenômenos e estruturas que Pierre Renouvin chamou de "forças profundas" na vida internacional, que transcendem os Estados como atores exclusivos e dão às nações uma "porosidade” em relação a processos transnacionais. Desde as últimas três décadas do século XIX, o mundo tem assistido à expansão das empresas multinacionais, a crises econômicas e financeiras de alcance universal, a escândalos internacionais, a processos de intensificação e difusão de práticas culturais e científicas e de correntes ideológicas e políticas de caráter mundial (socialismo, comunismo, fascismo, liberalismo, diversos tipos de movimentos religiosos e de organizações internacionais). Destaca-se, por sua peculiar importância na política mundial, a Internacional Comunista. Entretanto, essas tendências não anularam a ação estatal e, pelo contrário, em certas conjunturas potencializaram-na: as guerras entre as grandes potências chegaram a ter, assim, um alcance universal ${ }^{4}$. Também é preciso recordar que, ao iniciar-se o século XX, grande parte da população do mundo não vivia sob a jurisdição de Estados soberanos, mas inseriam-se no marco de diversas formas de dominação colonial e semicolonial. Um resultado visível das últimas cinco décadas é, por isso, a multiplicação de Estados independentes no cenário internacional.

Na realidade, o peso ainda vigente dos Estados nacionais, particularmente o das grandes potências, faz-se mais visível no plano político, estratégico e militar, como mostram a Guerra do Golfo e o processo posterior de negociações e conflitos entre os países líderes em relação a diversos pontos “quentes” da agenda internacional (o caso da ex-Iugoslávia, Somália, Cuba, Irã e Líbia, etc), assim como as discrepâncias a respeito do controle e desenvolvimento de armas nucleares dentro do ainda vigente monopólio atômico. Tudo isso tem-se refletido na visível “crise” dos organismos internacionais, como as Nações Unidas, cuja influência como ente supra-estatal parecia afirmar-se progressivamente ao final dos anos 80 e início dos 90 . O processo atual não marca, assim, o fim do sistema interestatal, pois intensifica-se o papel dos Estados, considerando várias grandes potências no cenário internacional ${ }^{5}$. Ao mesmo tempo, ainda que visivelmente haja uma considerável diminuição da presença e poder de decisão do Estado no que concerne aos países periféricos, muitos dos quais lograram desempenhar no passado um papel significativo por meio do movimento de países "não-alinhados": sua maior dependência dos mercados mundiais e as políticas de ajuste estrutural reduziram neles a capacidade de forças locais de utilizar o aparato do Estado na busca de maior poder interno e autonomia internacional. 
Por estas razões, o processo de reformulação da força e debilidade dos diversos Estados tem sua base não na extinção, mas na estruturação/ desestruturação dos espaços nacionais, tendo em conta o poder econômico e político de cada um deles e a diversidade das sociedades, culturas e histórias.

O fim do império Soviético, por exemplo, caracterizou o período como de emergência de nações outrora apagadas no Leste que reivindicaram seus direitos de constituir-se como Estados. Em alguns casos, como o iugoslavo - em que inicialmente houve desacordos entre as potências ocidentais -, assiste-se ao retorno de nacionalismos "fundamentalistas", a exemplo do que acontece no Oriente Médio e Afeganistão, ao mesmo tempo em que crescem as correntes neofascistas e nacionalistas retrógradas na Europa e nos Estados Unidos. Esses fenômenos ligam-se a fatores históricos ou constituem uma resposta à globalização como signos de resistência de valores culturais ameaçados, mas também expressam uma tendência contraditória inerente ao próprio processo econômico e político em curso na ordem mundial. Assim, as forças internacionais têm engendrado no establishment norte-americano disjuntivas nacionalistas (como as de vários candidatos a eleições presidenciais), diante da necessidade de afirmar a presença dos Estados Unidos no cenário internacional.

Tanto diplomatas, como Kissinger, quanto economistas, como Thurow e Reich, são representativos dessa tendência. Para Kissinger, por exemplo, o fim da bipolaridade mostrou uma crise de hegemonia no sistema internacional, tornando visível no plano político a já existente multipolaridade econômica e os "graus de liberdade" para as potências emergentes que oferecia a ausência de um inimigo único juntamente com o notório debilitamento norte-americano. “A inexistência de uma ameaça ideológica ou estratégica - assinala Kissinger deixa as nações livres para seguirem uma política exterior sustentada em seu interesse nacional imediato" em um sistema internacional "caracterizado por 5 ou 6 grandes potências e uma multiplicidade de Estados menores” 6 . Não haverá pax americana ou alemã ou japonesa, "a hegemonia do sistema capitalista não corresponde a de nenhuma potência ou nação capitalista individual”"

De um ponto de vista econômico, Thurow chega a conclusões parecidas procurando encontrar as vantagens competitivas dos Estados Unidos, em um livro com um subtítulo sugestivo: A batalha econômica entre Japão, Europa e América. Robert Reich, parafraseando Adam Smith, fala, por seu turno, do "trabalho das nações”, e Paul Krugman, criticando ambos os autores, parte de um ponto de vista distinto, a denúncia da "falsa competitividade" das economias nacionais, para chegar a uma conclusão parecida: os Estados-Nações gozam de boa saúde nos países desenvolvidos porque o núcleo de suas economias não depende dos mercados externos ${ }^{8}$.

Um recente artigo da The Economist, cujo ideário liberal não se pode questionar, assinalava de forma alarmada que, ainda que os mercados tendam a 
ser cada vez mais globais, nos Estados industrializados os gastos públicos aumentaram notavelmente nos últimos anos. Uma análise histórica mostra que esses gastos com relação ao PIB tiveram um incremento médio, para o conjunto desses países, de $27.9 \%$ em 1960 para 42.6\% em 1980 e 45.9\% em 1996. Estados Unidos e Grã-Bretanha, paradigmas das novas políticas econômicas, não viram diminuir significativamente seus gastos públicos nos últimos 20 anos ${ }^{9}$.

Portanto parece prematuro imaginar que os espaços nacionais tendam a desaparecer, dissolvendo-se em um contexto mundial global. Enquanto certos países mantêm ou reforçam seus aparatos estatais e outros desestruturam-se ou fragmentam-se, emerge o nacionalismo em várias regiões do globo e diversas comunidades reivindicam um Estado próprio para afirmar processos de consolidação nacional.

Finalmente, é necessário ressaltar que os próprios projetos de integração regional, ao mesmo tempo em que tendem a comprometer as soberanias nacionais, expressam uma tendência à constituição de supra-soberanias que contradizem também os pressupostos da “aldeia global”. Com todas as críticas que é possível apontar em relação a sua dificultosa institucionalização, a União Européia, que já tem instituições políticas em funcionamento (o Parlamento Europeu) e uma densa burocracia em Bruxelas e Estrasburgo, é o exemplo que mais caminha nessa direção. A futura moeda única européia participa igualmente de ambos os fenômenos: vai comprometer as soberanias estatais no manejo de um dos pilares do Estado moderno, o instrumento monetário, mas vai criar também um padrão de medida de valor exclusivamente europeu, representando essa exclusividade um desafio econômico frente ao resto do mundo.

O MERCOSUL está ainda longe da realidade européia. Carece de instituições estáveis e, sobretudo, de mecanismos políticos. Mas as discussões a respeito de uma ampla agenda de temas comuns - ALCA, Conselho de Segurança das Nações Unidas, OTAN - transformam cada vez mais o espaço comercial em um espaço de negociação política e econômica em relação aos demais países e regiões. Da coordenação das políticas macroeconômicas e comerciais até a das políticas exteriores, um amplo espectro de questões que podem comprometer a soberania de cada um dos Estados participantes vislumbra-se num horizonte próximo. No entanto, e mais ainda no caso do MERCOSUL, integrado exclusivamente por países em desenvolvimento, a unidade regional incrementa o poder negociador de cada nação separadamente. Como aconteceu com os devastados países da Europa Ocidental no segundo pós-guerra, as sociedades devastadas da década perdida do nosso Cone Sul latino-americano podem reforçar sua posição internacional construindo uma aliança regional que fortalecerá sua presença no mundo. Os Estados-Nações, longe de desaparecerem, descobrem novos meios de persistir em um mundo globalizado. 


\section{Notas}

1 Gilles Breton. “La globalización y el Estado: algunos conceptos teóricos”. Em M. Rapoport (comp.), Globalización, Integración e Identidad Nacional. Buenos Aires, 1994, pp. 20-21. Cf. também Juan Archibaldo Lanús. Un Mundo Sin Orillas. Nación, Estado y Globalización. Buenos Aires, 1996.

2 Cf. François Bédarida e Nicolas Roussellier. "Nations, peoples and State Forms”. Em Proceedings, XVIIIth International Conference of Historical Sciences. Montreal, 1995, pp. 3-23.

3 J. Letourneau. L’Economie Migrante. Essai sur les Temps Postkeynésiens. Coloquio Canada, Nafta and the Pacific Rim: nov. 1993, pág. 16.

4 Cf Mario Rapoport. "Una teoría sin historia?. El estudio de las relaciones internacionales en cuestión?” Em Ciclos en la historia, la economía y la sociedad, № 3, 1992, pp. 147-160.

5 Cf. Raúl Bernal-Meza. "La globalización: un proceso y una ideología?” Em Realidad Económica, № 139, 1996, pág. 96.

6 Henry Kissinger. La Diplomacia. México, 1995, pág. 802.

7 Luciano Martins. “A reorganização do poder mundial.” Em Brasil e as tendências econômicas e políticas contemporâneas. Brasília, 1994, pág. 20.

8 Ver Lester C. Thurow. Head to Head: The Coming Economic Battle Among Japan, Europe and America. Nova York, 1992; Robert Reich. El Internacionalismo "Moderno". La economia internacional y las mentiras de la competitividad. Barcelona, 1997.

9 “The future of the State”. Em The Economist, 20 de set. 1997. O título da capa da revista é: "The visible hand. Big government is still in charge". 